\section{$\underset{\text { hommes }}{\text { \& migrations }}$}

\section{Hommes \& migrations}

Revue française de référence sur les dynamiques

migratoires

$1288 \mid 2010$

Langues et migrations

\title{
Nell Freudenberger, Le Dissident chinois
}

Paris, Éditions Quai Voltaire/La Table ronde, 2010, 445 pages, $23 €$

\section{Mustapha Harzoune}

\section{OpenEdition}

1 Journals

\section{Édition électronique}

URL : http://journals.openedition.org/hommesmigrations/900

DOI : 10.4000/hommesmigrations.900

ISSN : 2262-3353

\section{Éditeur}

Musée national de l'histoire de l'immigration

\section{Édition imprimée}

Date de publication : 1 novembre 2010

Pagination : 178

ISSN : 1142-852X

\section{Référence électronique}

Mustapha Harzoune, « Nell Freudenberger, Le Dissident chinois », Hommes \& migrations [En ligne],

1288 | 2010, mis en ligne le 29 mai 2013, consulté le 22 septembre 2020. URL : http://

journals.openedition.org/hommesmigrations/900; DOI : https://doi.org/10.4000/hommesmigrations. 900

Ce document a été généré automatiquement le 22 septembre 2020.

Tous droits réservés 


\title{
Nell Freudenberger, Le Dissident chinois
}

Paris, Éditions Quai Voltaire/La Table ronde, 2010, 445 pages, $23 €$

\author{
Mustapha Harzoune
}

\section{RÉFÉRENCE}

Nell Freudenberger, Le Dissident chinois, Paris, Éditions Quai Voltaire/La Table ronde, 2010, 445 pages, $23 €$

1 Le Dissident chinois aurait pu s'appeler Mensonges. Car davantage que la dissidence en Chine ou l'arrivée pour une année d'un artiste chinois dans une famille américaine de Los Angeles, c'est aussi de mensonges et de dissimulations dont il est question dans ce livre. Pour ce premier roman, l'auteure, new-yorkaise âgée de 35 ans à sa sortie en 2006, figura dans la liste des meilleurs jeunes espoirs de la revue Granta. Nell Freudenberger avait écrit un premier recueil de nouvelles, Lucky Girls, traduit en 2008 chez le même éditeur.

2 L'histoire d'abord: la famille Travers s'apprête à recevoir, pour un an, Yuan Zhao, un artiste et dissident chinois. On peut imaginer le grand écart culturel, les préjugés des uns et des autres, les quiproquos et le temps laissé pour s'apprivoiser. Yuan, lui, est censé appartenir à l'avant-garde artistique pékinoise, membre du groupe de l'East Village à Pékin qui, au début des années quatre-vingt-dix, multiplia les performances et finit par être interdit par les autorités.

3 In fine, entre les Travers et Yuan Zhao, il ne se passera rien de tangible. Comme si le quotidien des membres de la famille tourneboulée et celui de l'artiste énigmatique, professeur à l'école de filles St Anselm's, filaient sur des rails parallèles.

4 L'année américaine est rythmée par les déboires de la famille Travers, les désillusions de Cece, la maîtresse de maison et les ennuis de Yuan Zhao avec quelques-unes de ses élèves. Le passé chinois de cet exilé offre, lui, l'occasion d'une formidable immersion au cœur du mouvement artistique pékinois de l'East Village. Ce qui remonte à la surface 
des existences ce sont les mensonges. Et les petits arrangements avec les représentations. La famille Travers est loin de correspondre à l'image de respectabilité et de conformité de l'American way of life, qu'elle s'efforce de rendre. Yuan Zhao, luimême, n'est pas en reste, qui multiplie les mensonges sur sa personne et sur son passé. En Chine, des années plus tôt, les parents de Yuan mentirent, eux aussi pour sauver leur peau...

5 L'art et la peinture chinoise forment le cœur du Dissident chinois. Un rouleau en est le prétexte. Celui d'un artiste de la fin du XIII ${ }^{\mathrm{e}}$ siècle et du début du XIV ${ }^{\mathrm{e}}$, Zhao Cangyun intitulé "Liu Chen et Ruan Zhao dans les monts Tiantai". Une œuvre que Yuan Zhao s'applique à recopier. Son auteur serait resté anonyme n'était une inscription ajoutée par un inconnu. Cela rejoint-il l'interrogation moderne sur la propriété d'une œuvre? La question traverse le roman car, quand l'argent entre dans la danse, de plus en plus lucrative, la question de savoir qui détient les droits sur les images devient pressante. Seraient-ce les artistes du groupe de l'East Village ou le photographe qui a immortalisé par ses clichés leurs performances artistiques? De même, un fil semble relier l'expérience lointaine de Zhao Cangyun à celle, dissidente et contestataire, des artistes chinois de la fin du $\mathrm{xx}^{\mathrm{e}}$ siècle. Enfin "Liu Chen et Ruan Zhao dans les monts Tiantai" offre l'occasion d'une réflexion sur l'exil : du retour impossible des marcheurs du rouleau de Zhao Cangyun à celui, anticipé, de Yuan Zhao. 